\title{
A COMMENTARY ON THE NEW ZEALAND ACCIDENT COMPENSATION SCHEME
}

\author{
LEWIS N. KLAR*
}

\begin{abstract}
The author analyzes the no fault insurance scheme operating in New Zealand as an alternative to common law tort law.
\end{abstract}

\section{INTRODUCTION}

The Final Report of the Ontario Task Force on Insurance, May 1986 (hereinafter referred to as the Slater Committee Report) contained three important recommendations:

B.28 In the short term, a new accident compensation scheme should be implemented by the private insurance industry at least for automobile accident injury.

B.29 Ideally and as a medium-term objective, government should begin to work with the private insurance industry to design a universal accident compensation plan that would include compensation for all accidental injuries.

B.30 Eventually and in the longer term, federal and provincial governments should begin planning the co-ordination and rationalization of all existing first-party no-tort compensation schemes into a universal disability compensation program.

In arriving at these very far-reaching proposals, the Slater Committee concluded that tort law is failing, both as a system of compensation and deterrence, and that the modern day problem of injury compensation can be dealt with more efficiently and expeditiously through a first-party notort accident insurance system. Particular attention was paid to New Zealand's Accident Compensation scheme, a comprehensive program which compensates all persons injured by accident, regardless of fault, while eliminating the right to sue in all cases of personal injury. The Slater Committee Report, both in the main body of the Report and in Appendix 15 , commented very favourably on the New Zealand scheme, leaving the general impression that it has been operating efficiently, equitably and economically, without major problems. For example, the Slater Committee Report states:'
It would certainly appear that many observers agree that the New Zealand accident compensation scheme is far superior to the system it replaced. It provides a much wider range of injured persons with a high level of income maintenance and other more moderate benefits. It provides those benefits, in the large majority of cases, efficiently, quickly and at very low level of administrative cost. The overall cost of the scheme is moderate and certainly cheaper than retention of the pre-1974 system.

In view of the fact that the New Zealand Accident Compensation scheme has become the "role model" for other proposals regarding nofault compensation programs it is essential that reform proposals fairly evaluate and assess the successes and failings of the New Zealand scheme. It is difficult for Canadians, far removed from the New Zealand scene, to assess, for themselves, the virtues and vices of the New Zealand program. We are dependent on the writings and perceptions of others, mainly academics or those involved in the program, who comment on the scheme, influenced by their own biases and preferences. It is with respect that I say that the Slater Committee Report has not presented a fair or balanced view of the current operation of the New Zealand Accident Compensation

- Lewis N. Klar, Professor of Law at the University of Alberta.

1. Appendix 15, at 349. 
program. Far from being a program which "continues to operate efficiently, expeditiously and fairly"2 the New Zealand Accident Compensation program is presently undergoing serious difficulties, especially in the area of tremendous cost escalation, and has been reported as being "in danger of collapse". ${ }^{3}$

This Note will comment on the New Zealand Accident Compensation scheme. It will refer extensively to the Review By Officials Committee Of The Accident Compensation Scheme, August 14, 1986 (hereinafter referred to as the Review Committee). This important document is the Report of a committee set up by the New Zealand government in 1985 to review the scheme. The members of the review committee were those most closely involved in the scheme's operation - including the Chairman of the Accident Compensation Corporation (the A.C.C.), the Deputy Managing Director (Policy) of the A.C.C., and senior officials in the Departments of Social Welfare, Labour, Health, and Treasury. The Note will also refer to an article previously published by this author: New Zealand's Accident Compensation Scheme: A Tort Lawyer's Perspective (1983) 33 U. of T.L.J. 80. The author spent seven months in New Zealand as a Visiting Lecturer at the University of Auckland in 1980.

\section{CHRONOLOGY OF THE NEW ZEALAND SCHEME}

The Review Committee sets out a brief chronology of the accident compensation scheme:

In 1966 a Royal Commission (hereinafter referred to as the Woodhouse Report) was established to report on compensation for damages for incapacity or deaths arising out of accidents. Despite the fact that the terms of reference for the Commission were specifically restricted to injuries suffered by workers, the Commission interpreted its mandate more widely and extended its inquiry and subsequent recommendations to cover all persons, workers and non-workers, injured at work, at home, or at play.

The first legislation was passed in 1972 and was limited to earners.

Amendments were passed in 1973 and in 1974, the scheme was extended to non-earners.

In 1975 a committee was established to investigate extending the scheme to sickness but this committee was disbanded in 1977 .

In 1980 recommendations were put forward to change benefits provided under the Act which would have had the effect of de-emphasizing shortterm disabilities but because of significantly adverse public reaction these proposals were withdrawn.

In 1981 there were some administrative changes.

In 1982 the method of funding was changed and employers' obligations to pay $100 \%$ of an injured worker's salary during the first week of disability was reduced to $80 \%$.

In 1985 a Committee of Officials was set up to review the scheme and in August 1986 the Committee reported.

2. Slater Committee Report, at 68.

3. Editorial, The Evening Post, Tuesday, August 19, 1986.

4. Volume 2 Appendix I, Page 85. 


\section{THE LINK BETWEEN TORT LAW AND NO-FAULT SCHEMES}

One of the most critical aspects of the New Zealand Accident Compensation scheme, the Woodhouse Report, and the Ontario Slater Committee Report is the link which they draw between the law of torts and no-fault schemes. The goal of more comprehensive programs for the disabled is achieved at the cost of abolishing private rights of action.

The common law of torts is not an accident compensation program for the needy or disabled. Comprehensive compensation programs for the disabled do not "replace" tort law, even if the "funds" used to support tort law are channeled into these other programs. The existence of a system of private rights of action is not incompatible with the existence of social insurance programs. Except for New Zealand, systems of private rights of action and social insurance or welfare programs to provide for the disabled or needy co-exist. Canadian tort law and social insurance or welfare programs, medicare, and other programs provide an excellent example of this co-existence.

The objectives and ideology of a system of private rights of actions differ significantly from the objectives and ideology of systems of social insurance or welfare. To compare the two programs is largely meaningless and misleading. Tort law must stand or fall on its own merits. So must nofault programs. Arguments about the strengths and weaknesses of tort law tell us nothing about the strengths and weaknesses of comprehensive compensation programs which are implemented to supplement or "replace" tort law. If the economic and social costs of tort law cannot be justified by the benefits which tort law brings, it should be reformed or abolished. Having done that, society must decide how it can use the "savings", if indeed there are any, most equitably and efficiently to accomplish other goals.

It is not the purpose of this Note to debate the strengths and weaknesses of tort law. It must be stated however, that the author is firmly convinced that tort law, despite its areas of weakness, is vital to a just and safe society and that to abandon it would be a serious mistake. Certainly the Slater Committee Report has not presented a very compelling case that the costs of a system of private rights of action outweigh its benefits. The Report focused on two objectives of tort law: deterrence and compensation, overlooking almost entirely questions of justice, punishment, education, and the ombudsman function. It is clear that these functions operate differently depending upon the type of action, the conduct, the interest protected, the parties and so on. That they do operate, however, seems to this author to be incontrovertible, although one may demonstrate weaknesses and inadequacies in their mode of operation.

In view of the fact that tort law and no-fault schemes operate differently and for different purposes, why link the two? The reason is clearly financial. This was the case in New Zealand as conceded by Geoffrey Palmer, the chief architect of the New Zealand scheme: ${ }^{5}$

Strategically it was essential to the Woodhouse style of reform that a compelling case be developed against the common law. If the common law survived, a comprehensive system

5. Palmer, Compensation for Incapacity: A Study of Law and Social Change in New Zealand and Austrailia 1979, at 25. 
of compensation for injury was unattainable. If the common law remained, the financial logic of the reform was destroyed - new sources of revenue would be needed rather than making better use of the existing money. The Woodhouse tactic was to divert the money flowing through the compulsory insurance systems to a new comprehensive scheme. Unless the case against the common law was utterly devastating there would be a risk of compromise solution.

The decision to link tort law to the new accident compensation scheme in New Zealand by abolishing the right to sue and using the funds which were used to support tort law to assist in funding the new scheme has proven to be the major problem for New Zealand's scheme. Victims of "accidents" caused by the deliberate, reckless or negligent conduct of others expect that they will be treated justly by tort law or by whatever compensation scheme is introduced to replace common law rights. Attitudes related to concepts of "fault" and "justice" do not disappear with the introduction of no-fault schemes. Compensation schemes which eliminate common law rights must take into account the rights and attitudes of victims of wrongs. This distorts no-fault compensation schemes from the outset and makes it difficult to formulate equitable and efficient policies which are consistent with the ideology of comprehensive social insurance programs but which are not necessarily consistent with fault-based compensation. This has been the New Zealand experience. The scheme started out with the built-in inequity of compensating accident victims but not other equally needy disabled. Altering this inequity and reforming the program has not been possible. The giving up of common law rights to sue in exchange for just and adequate compensation rights is viewed in New Zealand as a type of "social contract" which cannot be breached. If it is breached the demand for access to the courts revives.

Jurisdictions contemplating a New Zealand style reform must keep this in mind. Unless victims of wrongs can be convinced that they are no different than victims of illness, innocent accidents, or even those who engage in risky activities and injure themselves, the problem of devising a fair and efficient compensation program will persist. Because issues of wrong-doing are different from issues of compensation for the needy and disabled, societies must maintain programs which accomplish different goals.

\section{THE COSTS OF NEW ZEALAND'S ACCIDENT COMPENSATION SCHEME}

Proposals to replace tort law with no-fault schemes generally are supported by the argument that this is a cost efficient decision. In discussing the New Zealand scheme, for example, the Slater Report states: ${ }^{6}$

Overall, one can conclude that the money flowing through the workers' compensation system and the automobile fault/insurance system was sufficient to finance the no-fault system and that the scheme is almost certainly cheaper than a continuation of the old system. It was estimated in 1982 that the accident compensation scheme resulted in annual savings of over $\$ 100$ for the owners of private motor vehicles. Similar results have been predicted in Australia and the United Kingdom. It has been claimed that a similar scheme in Australia would save the country $\$ 1$ million per day and the Pearson Commission found that a move to no-fault would result in an annual savings of 84 million pounds.

6. Supra, n. 2 at 346. 
The Slater Report adds that "by all reports [the New Zealand scheme] continues to operate efficiently, expeditiously and fairly". The "cost" argument is therefore an important one, and should be examined closely. What are the costs of the New Zealand scheme?

\section{A. DIRECT COSTS}

In order to appreciate the direct costs of New Zealand's program, a brief review of the benefits and sources of funds is helpful. All persons who suffer "personal injury by accident" regardless of fault are covered by New Zealand's scheme. This includes persons who are injured by accident in any activity, no matter how, with few exceptions. The most dramatic example of this occurred in 1983 when a prisoner who had been convicted on two murder charges attempted to escape from prison and injured himself in his escape attempt, breaking a hip and an ankle. The prisoner who was serving a life term received $\$ 18,300$ in accident compensation benefits for his $49 \%$ disability. The only exception to criminals receiving compensation is where the person is injured during a criminal activity for which he is subsequently charged, convicted and sentenced to prison. In this case there is a discretion to refuse to award compensation. As well where someone wilfully self-inflicts personal injuries or where there is a suicide, rights to compensation may be denied. The scheme does not cover disability which results from illness as opposed to accident, a matter which raises serious practical and ideological difficulties for the scheme.

The major benefits which persons covered may receive include earningsrelated compensation (ERC) for injured persons and survivors, noneconomic loss $(\$ 10,000$ for pain and suffering and loss of enjoyment of life; $\$ 17,000$ for permanent loss or impairment of bodily function), medical, hospital, and dental treatment, conveyance for medical attention, funeral expenses and other rehabilitation expenses. ERC is fixed at $80 \%$ of earnings (up to a ceiling) after the first week. During the first week the employer pays the $80 \%$. The sources of the funds are employers, motor vehicle levies, and general revenues.

The issues relating to levels of benefits, sources of funds, and options for reform for the New Zealand scheme are outside the scope of this Note. They were thoroughly reviewed in the Review by the Officials Committee. However, in order to dispel the impression left by the Slater Report that "the overall cost of the scheme is moderate and certainly cheaper than retention of the pre-1974 system"' it is necessary to refer to some of the Review Committee's Report.

The Review Committee was mandated to examine the scheme "prompted by inequities in treatment of illness and accident disabled and concern about escalating costs of the present accident compensation scheme". The Review Committee was asked to adhere to the basic principles of the accident compensation scheme.

The Review Committee stated quite clearly at the outset of its Report:

The Accident Compensation Corporation's annual report to Parliament for the financial year ended 31 March 1986 is convincing evidence of cost escalation. Indeed the financial viability of the current scheme is open to question given the massive cost blow-out in

7. Supra, n. 2 at 349. 
compensation which has occurred. This has caused a much more rapid run-down in reserves than was originally forecast. To maintain the current scheme at current levels will require substantial increases in levies each year. For example, in the 1987/88 year the increase in the employers levy could be in excess of $100 \%$.

The Committee is firmly of the opinion that the scheme cannot continue in its present form. (emphasis added)

The Review Committee closely examined several options for change. It favoured modifying the existing scheme, eliminating benefits for minor injuries thereby "shifting some of the costs directly back to the consumer", and extending a modified scheme to all disabled. The Committee stated that continuing coverage of minor short-term injury or extension to minor illness disability is not desirable.

The Committee recommended the abolition of lump sum payments. It forecast a $25 \%$ to $40 \%$ increase in lump sum payments in the $1986 / 87$ budget year and urged that there be no raising of the maximums for lump sums or indexing of lump sums until decisions on the future of the scheme were made.

\section{The Committee noted:}

During the course of the review there was a considerable public debate on the provision or otherwise of compensation for persons injured in the course of criminal activities, drunken driving and exposure to sporting and recreational hazards.

The Committee went on to ask:

Another question is whether objectives of accident compensation and sickness assistance may be different. The main argument is to what extent it is still relevant that many accidents are suffered through specific wrongdoing of other individuals. Although New Zealand has had a no-fault system in place for more than ten years, the concept of 'justice to the victim' is still important as a philosophical basis for policy. This review, however, is not in any position to assess the degree of that importance. (emphasis added)

In its discussion of the principles and objectives of the scheme the Review Committee posed the following issue:

The major issue now is whether a greater role for individual responsibility should and can be found in the scheme. The reasons for this change include:

The present incidence and distribution of costs is at best approximately related and at worst completely unrelated to the distribution of benefits. Is it fair or equitable that some in effect subsidize the higher risk of others?

While accidents are largely chance events, some people are in a position to influence outcomes at least at the margin. Currently there are only weak financial incentives that for instance encourage accident prevention programmes. It can be argued that the price of goods, services and activities should reflect their full costs, including social costs such as the costs of accidents. This is the efficiency argument. (emphasis added)

The Review Committee examined the impact of the scheme on the "external environment", namely the labour market, the health system and the social welfare system. It was especially concerned with the effect of the scheme on health services. It favoured "cost sharing and individual responsibility", namely shifting some of the costs of health care back onto the patient. It discussed how this could be done. In terms of social welfare programs, it noted how the disparity between the various programs produce inequity and creates incentives for injuries that are not clearly accidents or illnesses to be regarded as accidents, resulting in escalating costs for the accident compensation scheme. In terms of its effect on the labour market it noted the concern with "inherent work disincentives", the attempt to ascribe medical disorders to accidents, to exaggerate the severity of disabilities and, in the extreme case, to fabricate. It seemed to favour 
options which would provide appropriate incentives for return to work in the case of short-term injuries, without placing undue hardships onto the individuals. These options would in effect shift some of the costs for shortterm injuries back onto the victim, by reducing ERC, for example.

The rapidly escalating costs of the New Zealand accident compensation scheme are creating the most serious problems. It is useful to highlight some of these costs to demonstrate the dimensions of this problem.

The Woodhouse Report ${ }^{8}$ estimated that the cost of private hospital treatment and medical fees for the scheme would be $\$ 2.92$ million in 1967 plus a $20 \%$ contingency. In 1986 dollars, this estimate is about $\$ 24.5$ million. $\$ 98$ million was paid out by A.C.C. on medical care in 1985/86; in $1976 / 77 \$ 15.67$ million was paid out for medical costs, the equivalent of $\$ 47$ million currently.

The increases in total expenditures have been dramatic. The following Table, taken from the Review Report, indicates the growth in expenditures:

\section{Year Ended 31 March}

1975

1976

1977

1978

1979

1980

1981

1982

1983

1984

1985

1986

1987 (est.)
Total

32.7

59.2

81.3

102.8

114.7

122.0

149.8

192.4

253.1

284.6

340.1

454.5

545.6
\% Increase

81

37

26

11

6

22

28

31

12

19

33

The Review notes that 1987 expenditure is currently running ahead of estimates and that "the cost of the scheme has risen at a much faster rate than either price or wage indices".?

The Review details in considerable detail the specific increases. An overview of cost escalations is evident in the following figures obtained from Treasury sources and published in the September 13, 1986 issue of the New Zealand Listener:

In the period of March 1976 to March 1985, ACC payments for lost earnings rose $399 \%$.

In the same period, ACC payments for medical costs rose $524 \%$.

In the same period, ACC payments to non-earners rose $752 \%$.

In this period, the consumer price index was up $198 \%$, and average weekly wage up $187 \%$.

Ontario is not New Zealand and the problems of ACC in New Zealand would not necessarily apply to a scheme in Ontario. Schemes are different

8. Id., at 33, para 3.49 .

9. Id., at 37 . 
and problems can be avoided. The Review Committee did not have the mandate to recommend a return to tort law and did not do so although it is discussed as an option in some areas - medical malpractice for example. The Review Committee's Report is a detailed document and I have been selective. Having said all of that, however, it is naive and wrong to believe that New Zealand's program is working without experiencing very serious financial difficulties. One certainly cannot say that "the overall cost of the scheme is moderate", in light of the Review Committee's Report which makes it clear that the existing scheme cannot be continued in its present form.

What steps New Zealand will take, if any, to reduce the direct costs of the program are difficult to predict. If the recommendations for elimination of the lump sum, and a reduction of medical benefits and income replacement go forward, they will not do so without great controversy. This is what occurred when cuts to benefits were last proposed. There is already evidence of this reaction. The August 19, 1986 edition of The Evening Post in an editorial entitled "ACC in danger of collapse" wrote that the proposals represent "little short of a betrayal of the rights of all New Zealanders because their ability to sue should they suffer injury was given up in exchange for accident compensation". The editorial stated that "as our system collapses under the weight of claims that range from the tragic to the exploitive, our Royal Commission on Social Policy might have another look at Lord Pearson's report with a view to its application here". One will recall that the Pearson Report recommended that the right to sue not be abolished in England. The sentiments expressed in the Editorial, and in submissions presented to ACC when reductions in benefits were last proposed, clearly support the argument presented above. Eliminating tort law rights does not eliminate tort law attitudes, and makes reform of compensation programs, which would reduce benefits, unacceptable.

\section{B. INDIRECT COSTS}

It is more difficult, and somewhat speculative, to assess the "indirect" costs of an accident compensation scheme, such as New Zealand's. Indirect costs are costs of the program which are not reflected in the actual cost of administering the scheme and paying for the benefits. The social and economic costs to New Zealand from introducing accident compensation will vary depending upon the context. It is my submission that the common law of torts can reduce accident costs and hence its elimination will increase them. This factor will be variable, however, since tort law does not work as effectively in all areas. It is submitted that the following concerns are valid and must be taken into consideration.

\section{Deterrence}

To the extent that the common law of torts deters wrongful conduct which causes accidents, its removal and the failure to replace it with anything else, increases the costs of accidents to society. If the deterrent function is replaced by other mechanisms, e.g. increased use of criminal law, regulatory agencies, safety programs, and so on, then these are costs of the accident compensation program which must be calculated. 
The argument concerning the deterrent function of tort law is a controversial one. Some scholars believe tort law is an effective deterrent; others that it is not. There is no doubt that tort law does have a deterrent effect in at least some areas. This after all is what so-called "defensive" medicine is all about. When liability insurance becomes unaffordable or even unobtainable as a result of tort law judgments, is this not deterrence? ${ }^{10}$ The New Zealand Review Committee itself clearly recognized that all accidents are not chance events and some people can influence outcomes. To deny this would be ludicrous. All activities obviously do not have the same element of risk or utility. The fact that accident compensation schemes adopt "rewards" and "penalties" to influence levies indicates their belief in the concept of deterrence.

In some areas in particular, concerns have been expressed regarding the absence of deterrence introduced into New Zealand society by the introduction of the scheme. Margaret Vennell, a New Zealand academic, expert on A.C.C., submitted a Brief to the Review Committee in which she stated that "in New Zealand as a result of coming into force of the Accident Compensation Act 1972, manufacturers and importers are not prevented by the fear of tort liability from placing unsafe products on the market". She submitted that a system of levies on manufacturers and importers should be introduced as well as product liability legislation giving the A.C.C. the right to sue. Ms. Vennell also expressed concern regarding occupiers' liability.

In the area of automobile accidents, one tends to think that deterrence by tort law is not effective, in view of other factors, such as criminal law, fear of injury to the driver, unpreventable human error and so on. One must not forget that automobile accidents are not always caused by ordinary human error of drivers. Accidents are caused by negligence, recklessness, drunkeness, defective vehicles, poorly designed highways, inadequate warning devices and so on. How will these factors be investigated in a no-fault scheme? What will be the costs of these procedures? What will be the costs if no procedures are instituted? How effective will these procedures be? As will be discussed shortly, the New Zealand experience with accident safety and prevention in the context of the scheme has been a very unsatisfactory one.

\section{Education and publicity}

The argument concerning the educative and publicity functions of tort law is similar. To the extent that these functions operate, accidents are reduced and costs are lessened. How will these be replaced? What will the costs of these other mechanisms be, and how effective will they be?

The New Zealand experience in the area of accident prevention by deterrence, education, publicity, and the use of sanctions has been unsatisfactory. The Review Committee notes that although there is a system of rewards and penalties in the New Zealand scheme, "penalties have not been used" and "rewards were last used in 1984/85 and amounted to less than $1 \%$ of the total levies collected". The Review Committee states that "administrative difficulties preclude greater use of this facility". Even

10. Let us recall that this is why the Slater Committee was asked to report in the first place! 
strong advocates of the New Zealand scheme, such as Professor Ison, are very critical of this aspect of the program. Professor Ison noted that there "is no use of real sanctions for the enforcement of health and safety regulations", few regulations, fewer prosecutions, and that "the system seems designed to avoid, rather than to promote, the use of worker pressure to bring about compliance". ${ }^{11}$

The Review Committee Report notes that expenditures by the Accident Corporation on accident prevention have actually been declining both in real terms (total amount in constant dollars) and as a percentage of total expenditure. ${ }^{12}$

Can accident prevention and safety be effectively promoted without using the deterrent, educative, and publicity functions of tort law, and if so, at what cost? Can accidents be reduced when those who cause them bear no financial responsibility for them? These are difficult questions which the Review Committee faced. The Review conceded that the basis of choosing between alternative funding sources for compensation benefits required one to distinguish the appropriate level of community versus individual responsibility. In this task the Review stated that "it is much more difficult to assign individual responsibility for cost without also assigning fault". ${ }^{13}$ The Review admitted that "there is a conflict between the concept of community responsibility and the correct assigning of costs."14

Another way of approaching the question of accident prevention and the effective assignment of costs is to see where accidents are occurring and to determine who should pay for them. The Review notes, for example, that about $38 \%$ of non-working accidents, excluding motor vehicle accidents, is caused by sporting accidents. This represents about $15 \%$ of compensation costs - about \$75 million dollars. ${ }^{\text {is }}$ It is not unfair to ask who should pay for these "accidents"?

\section{Other costs}

For whatever reasons, accident claims and the number or reported accidents have increased dramatically since the introduction of the New Zealand scheme. Whether this is the result of the generosity of the scheme, lack of incentives to avoid accidents or minimize claims, abuse, or whatever, an increase in accident claims carries with it not only an increase in direct costs paid out in the form of benefits but an increase in indirect costs as well. It is not being suggested that the New Zealand scheme is overly generous, or not generous enough; merely that when a no-fault scheme is costed these increased and often unanticipated costs are a real factor. Studies done in New Zealand in the 1970's indicate that there was a significant increase in reported accidents in the freezing works industries after the accident compensation program was introduced. This resulted

11. Ison, Accident Compensation: A Commentary On The New Zealand Scheme (1980), at 161 162.

12. Supra, n. 7 at 115.

13. Id. at 62.

14. Id. at 66 .

15. Id. at 80 . 
not only in escalating direct costs but an increase in indirect costs, such as lost manpower. One study revealed that lost time injuries increased by $92 \%$ in the first two years of the scheme, the accident rate in some works doubled, and the scheme was subject to some abuse. ${ }^{16}$ Another study indicated that since the introduction of the scheme the direct cost to the meat freezing industry for accidents had doubled. ${ }^{17}$ The figures on the escalation of accident compensation expenditures also indicates the extent of this problem.

Another aspect of increased indirect costs relates to the relationship of the accident compensation program to other social programs. It is universally agreed that the introduction of the accident compensation scheme has produced an inequitable, two-tier program. There are those who are entitled to accident compensation benefits, and those who are not and who must rely on other programs. According to some observers, the disparity between the levels of benefits available has had unanticipated results. It has been argued that "the New Zealand government has been forced to make substantial adjustments to other income maintenance programs (especially retirement pensions) which were in no way foreseen by those arguing for accident reform, and which may set a level of welfare redistribution beyond the immediate capacity of the national economy."18 As well, as indicated in the Review, there has been the tendency to treat non-accident cases as accidents, in order to entitle the victim to the higher level of benefits. ${ }^{19}$

\section{THE DEVELOPMENT OF RIGHTS AND OBLIGATIONS}

Many of the rights which Canadians now enjoy were created and are protected by tort law. The right to bodily security, peace of mind, and the protection of property are protected by various tort actions. This is not to say that rights and obligations have not been and cannot be created in other ways, primarily by legislation. But in the main, it is the common law of torts which is the source of many of our rights.

In a New Zealand style accident compensation scheme, how are rights and obligations to be created, defined, and maintained? It is one thing to provide compensation to a disabled person, but quite another to say that a person has a right to a specific protection, which obligates another to conduct himself in a specific way. For example, in New Zealand the fact that a person is entitled to compensation for an accident occurring on a ski hill does not imply that the skier and others have a right to expect that a ski hill operator will design his resort in a safe way and certainly does not oblige the operator to do so. Whatever regulations and sanctions there will be must arise from some other source. This, of course, is the same for every accident which occurs.

16. Nordmeyer Report, 1977, discussed by Palmer, supra, n. 5 .

17. See Berkowitz, The Economics of Work Accidents in New Zealand, Industrial Relations Research Monograph No. 5, 1979, referring to a New Zealand Freezing Companies Association study.

18. Ogus, Cornfield, and Harris, Pearson: Principled Reform Or Political Compromise?, [1978] Ind. L.J. 143, at 149.

19. It has been reported that the ACC Managing Director states that "in Wellington at least some doctors treat sores picked up in school swimming baths as accidents". NZ Listener, Sept. 13, 1986. 
Let us look at some concrete examples which have occurred in tort law since the introduction of New Zealand's compensation program. In New Zealand, is a doctor obliged to fully inform his patient of all material risks of injury from a proposed treatment, as was established in Reibl v. Hughes? ${ }^{20}$ In New Zealand, what are the legal responsibilities of municipalities and other government agencies in reference to the safe design of roads and highways ${ }^{21}$, or in regards to the making of policy and the enforcement

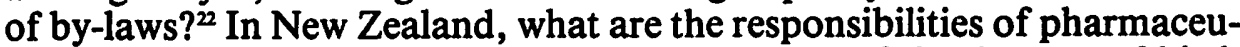
tical companies in relation to warning consumers of the dangers of birth control pills? ${ }^{23}$ If property damage occurs access to the courts to determine these issues is, of course, possible. If there is no property damage, those who think that they have rights and others obligations must, without the expectation of compensation, pursue these matters with the appropriate authorities. The costs of this type of system to society will only be determined after a longer period of time.

\section{CONCLUSION}

Victims of accidents which are not caused by the fault of other persons are no more deserving than victims of other types of inevitable accidents, illnesses or other misfortunes. The ideological dilemma implicit in selecting for special treatment one category of the disabled in preference to others is a problem of New Zealand's Accident Compensation scheme, which seems to be very difficult, if not financially impossible, to resolve.

It has been the submission of this Note that creating an accident compensation scheme which eliminates the right to sue is wrong, and creates a fundamental dilemma for the development of a logical, efficient and equitable scheme. People are concerned about fault, individual accountability and personal responsibility, and continue to be concerned about these values under a no-fault program.

In several places of the Review Committee's Report this is implicitly, if not explicitly, understood. The call for "individual responsibility" by making victims responsible for a portion of the costs of accidents, is not far removed from the notion of "individual responsibility" of wrongdoers and wrongdoing victims under tort law. In discussing the elimination of lump sum payments under a modified scheme the Review Committee gives this option:

A further option is to reinstate a victim's right-to-sue for non-economic loss. This would take the responsibility for this aspect of loss away from A.C.C. and put it back in the Courts. The advantages are that claims for minor injuries and where there was significant contributory negligence would probably not be pursued, and that special circumstances of a case might be better taken into account. However, this option would also have most of the disadvantages of the legal lottery that the scheme replaced. There would also be the disadvantages of having a dual system of compensation. This might be seen as a departure from the principle of no fault. However, the adoption of the principle of no fault was essentially in respect of the basis for compensation, rather than the elimination of

20. (1981), 114 D.L.R. (3d) 1 (S.C.C.). This is quite separate from the question whether a patient in New Zealand is even presently entitled to accident compensation if this adverse risk occurs, which has become the subject of growing literature.

21. Malat v. Bjornson (1981), 114 D.L.R. (3d) 612 (S.C.C.).

22. City of Kamloops v. Nielsen (1984), 29 C.C.L.T. 97 (S.C.C.).

23. Buchan v. Ortho Pharmaceutical (1986), 35 C.C.L.T. 1 (Ont. C.A.). 
responsibility. A variation on this option is for the injured person to sue A.C.C. for noneconomic loss (as in the Victorian scheme), and so have the award determined by a court.

A return to private rights of actions, even if limited, is gradually creeping back into the New Zealand debate. Recently, the right to sue for exemplary damages was re-instituted by the New Zealand Court of Appeal. Margaret Vennell has argued for the right to sue in products' liability cases. Palmer has conceded that the right to sue might be permitted in all actions for assault - interferences with the dignity of the plaintiff. The Review Committee raises the option of restoring access to the courts in some cases, such as medical malpractice.

The New Zealand Accident Compensation scheme is an ambitious and daring proposal. It is idealistic and humanitarian in approach. In my opinion, however, it overlooks issues of civil liberties and justice for the individual. The program has been in operation for only twelve years and is presently under severe scrutiny.

Canadian common law provinces have a system of civil justice which has developed over several centuries and in view of its scope and objectives works well. Canadians also have tremendous social security medical benefits, and other protections against misfortune. To abandon this system of co-existence of private rights and public protections would be a serious error. 